\title{
The anthelmintic drug flubendazole induces cell apoptosis and inhibits NF- $\kappa B$ signaling in esophageal squamous cell carcinoma
}

This article was published in the following Dove Medical Press journal:

OncoTargets and Therapy

\author{
Jiali Tao' \\ Hongmei Zhao' \\ Xiaochen $\mathrm{Xie}^{2}$ \\ Man Luo' \\ Zhiwei Gao' \\ Hong Sun' \\ Ziming Huang ${ }^{3}$ \\ 'Department of Emergency, The \\ Affiliated Huaian No I People's \\ Hospital of Nanjing Medical \\ University, Huai'an 223300, Jiangsu, \\ China; ${ }^{2}$ Department of Respiratory, \\ The Affiliated Huaian No I People's \\ Hospital of Nanjing Medical \\ University, Huai'an 223300, Jiangsu, \\ China; ${ }^{3}$ Department of Emergency \\ Surgery, The Affiliated Huaian No I \\ People's Hospital of Nanjing Medical \\ University, Huai'an 223300, Jiangsu, \\ China
}

Background and objectives: The nuclear factor kappa $\mathrm{B}(\mathrm{NF}-\kappa \mathrm{B})$ signaling is activated in esophageal squamous cell carcinoma (ESCC) and can be used as a potential target for antiESCC drug discovery. In this study, we aimed to investigate the function of flubendazole as a novel NF- $\mathrm{KB}$ inhibitor in ESCC cells.

Materials and methods: Cell Counting Kit- 8 assay was carried out to assess cell viability of ESCC cells. Flow cytometry and immunoblotting were performed to examine cell apoptosis. Immunoblotting assay was used to analyze the protein expression of NF- $\kappa B$ signaling. Luciferase assay was performed to explore the activation of NF- $\kappa$ B. Plasmids were transfected into ESCC cells using Lipofectamine ${ }^{\circledR} 2000$.

Results: In this study, the anthelmintic drug flubendazole was found to inhibit the activation of I $\kappa \mathrm{B} \alpha$ kinases (IKKs), block the activation of I $\mathrm{B} \alpha$, and decrease the phosphorylation of NF- $\kappa \mathrm{B}$ p65, which could be a novel NF-אB inhibitor in ESCC cells. We also found that flubendazole inhibited the cell survival of different ESCC cells and induced cell apoptosis in both EC9706 and TE1 cells. Moreover, overexpression of constitutively activated IKK $\beta$ markedly decreased the cytotoxic effect of flubendazole on EC9706 and TE1 cells. In addition, flubendazole also showed a synergistic effect on ESCC cells when combined with doxorubicin.

Conclusion: The results above demonstrated that flubendazole showed its anti-tumor action by suppressing the NF- $\mathrm{\kappa B}$ signaling pathway and suggested that flubendazole might be re-purposed for anti-ESCC therapy in clinic as a single agent or in combination with other anti-tumor drugs. Keywords: flubendazole, cell apoptosis, NF- $\kappa \mathrm{B}$, esophageal squamous cell carcinoma, re-purpose

\section{Introduction}

Esophageal squamous cell carcinoma (ESCC) is one of the most common and fatal malignancies in China and is considered as an aggressive cancer due to its poor prognosis and high mortality rate with a 5 -year survival rate of only about $20 \%{ }^{1,2}$ Although important progress in drug development has been made, there are still few drugs that have long-term benefits for the treatment of ESCC, ${ }^{3,4}$ which suggests that it is urgent to identify new drugs to improve systemic therapy for ESCC patients. One possible strategy is to screen the Food and Drug Administration (FDA)-approved drugs for targeting essential pathways in ESCC cells, such as the $\mathrm{NF}-\kappa \mathrm{B}$ signaling pathway. ${ }^{5,6}$

The nuclear factor kappa B (NF- $\mathrm{BB})$ system is involved in many diseases, including malignancies, diseases of immune system, metabolic diseases, and so on. ${ }^{7}$ The NF- $\kappa \mathrm{B}$ system consists of five structurally related monomeric subunits: RelA (p65), 


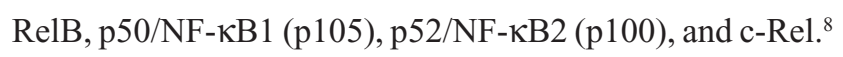
Among these, the p65/p50 complex is the most common active heterodimer. ${ }^{9}$ In normal status, the p65/p50 complex stays inactive because of binding with $\mathrm{I} \kappa \mathrm{B} \alpha$ in the cytoplasm. Some cytokines such as tumor necrosis factor $\alpha$ $(\mathrm{TNF} \alpha)$ and interleukin-6 (IL-6) can activate I $\mathrm{B} \alpha$ kinases (IKKs), and IKKs further phosphorylate IKB $\alpha$ and promote its ubiquitination for degradation through the proteasomal pathway, resulting in nuclear translocation and promoting

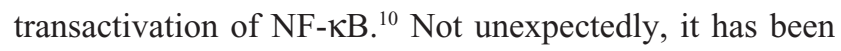
reported that $\mathrm{NF}-\kappa \mathrm{B}$ signaling is hyperactivated in many tumors, including ESCC. ${ }^{11}$ In tumor cells, the activation of $\mathrm{NF}-\kappa \mathrm{B}$ signaling mediates cell growth, cell proliferation, cell survival, and cell invasion. ${ }^{10}$

Studies have reported that NF- $\kappa \mathrm{B}$ signaling is overactivated in ESCC cells and primary tumor tissues, and its inhibition leads to decreased cell growth and cell proliferation. ${ }^{11}$ In addition, overactivation of NF- $\mathrm{KB}$ signaling could decrease drug sensitivity of chemotherapeutics in tumors..$^{5}$ Thus, targeting NF- $\kappa \mathrm{B}$ signaling has been an actively sought-after strategy for novel anti-tumor drug discovery, and a number of specific inhibitors have been reported for further clinical studies. In our previous study, flubendazole, an effective anthelmintic drug, was screened out to potentially inhibit $\mathrm{NF}-\kappa \mathrm{B}$ signaling by screening a library of FDA-approved

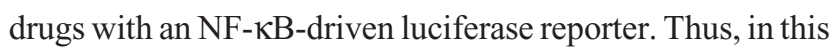
study, we focused on investigating the function of fluben-

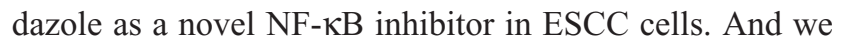
found that the anthelmintic drug flubendazole showed potent anti-ESCC activity by suppressing NF- $\kappa \mathrm{B}$ signaling, which indicated that flubendazole could be potentially repurposed as a chemotherapeutic drug for the treatment of ESCC.

\section{Materials and methods}

\section{Cells, culture, and chemicals}

ESCC cell lines including EC1, EC9706, KYSE70, KYSE140, KYSE450, TE1, and TE13 were provided by the Department of Pathophysiology, School of Basic Medicine, Zhengzhou University, China. ${ }^{12}$ The use of the cell lines was approved by the Institutional Review Board and Ethical Committee of the Affiliated Huai'an No 1 People's Hospital of Nanjing Medical University. HEK293 cell line was purchased from American Type Culture Collection (Manassas, VA, USA). All ESCC cell lines were cultured in RPMI1640 medium. HEK293 cells were cultured in DMEM. All media were supplemented with $10 \%$ fetal bovine serum, 100 units/mL streptomycin, and $100 \mu \mathrm{g} / \mathrm{mL}$ penicillin. Flubendazole and doxorubicin were purchased from SigmaAldrich (St Louis, MO, USA).

\section{Cell viability}

Viable cells of ESCC were analyzed by Cell Counting Kit-8 (CCK-8) assay according to the manufacturer's instructions (Dojindo, Kumamoto, Japan) as described previously. ${ }^{5}$

\section{Cell apoptosis analysis}

EC9706 and TE1 cells were treated with flubendazole for 24 hours, and then cells were prepared for Annexin V-FITC and PI stainings for 10 minutes. Then, stained cells were analyzed on a flow cytometer (Attune ${ }^{\circledR}$ NxT; Life Technology, Waltham, MA, USA) as described previously. ${ }^{13}$

\section{Immunoblotting}

Immunoblotting was performed as described previously. ${ }^{14,15}$ Whole cell lysates were extracted and equal amounts of total proteins were subjected to SDS-PAGE separation, followed by immunoblotting with specific antibodies. The primary antibodies PARP, Bcl-2, Bim, phospho-NF- $\mathrm{BB}$ p65 (p-p65)

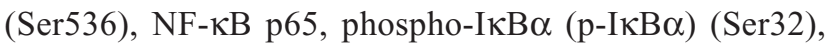
IкB $\alpha$, phospho-IKK $\alpha / \beta$ (p-IKK) (Ser176/180), IKK $\alpha$, IKK $\beta$, and GAPDH were purchased from Cell Signaling Technology (Danvers, MA, USA). Anti-Flag antibody was purchased from Medical \& Biological Laboratories (Tokyo, Japan). Anti-mouse and anti-rabbit immunoglobulin $\mathrm{G}(\mathrm{IgG})$ horseradish peroxidase conjugated antibodies were purchased from Santa Cruz Biotechnology, Inc. (Santa Cruz, CA, USA).

\section{Luciferase assay}

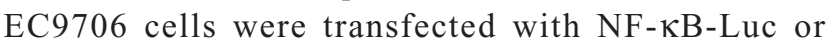
empty vector along with the internal control renilla using Lipofectamine $^{\circledR} 2000$ (Thermo Fisher Scientific, Waltham, MA, USA) for 24 hours. Then, cells were treated with TNF $\alpha$ or flubendazole for 12 hours, followed by luciferase assay with Dual-Luciferase ${ }^{\circledR}$ Reporter Assay System (Promega Corporation, Fitchburg, WI, USA) according to the manufacturer's instruction.

\section{Plasmid construction and gene transfection}

The human constitutively activated IKK $\beta(\mathrm{CA}-\mathrm{IKK} \beta)$ gene was amplified by PCR and cloned into pcDNA3.1 vector with a Flag tag as previously described. ${ }^{16}$ Plasmids were transiently transfected into EC9706 or TE1 cells using Lipofectamine $^{\circledR} 2000$ (Thermo Fisher Scientific) according to the manufacturer's instruction.

\section{Statistical analysis}

Student's $t$-test was used for significance analysis in the studies, and all statistical tests were two-sided. Statistical significance was defined as a $P$-value $<0.05$. 


\section{Results}

\section{Flubendazole inhibits cell survival and induces cell apoptosis in ESCC cells}

To evaluate the effect of flubendazole on ESCC cell survival, a panel of ESCC cell lines were incubated with flubendazole for 24 hours, followed by CCK- 8 assay. As shown in Figure $1 \mathrm{~A}$ and $\mathrm{B}$, flubendazole significantly inhibited the cell survival of seven ESCC cell lines in a concentrationdependent manner, but had less effect on HEK293 cells than ESCC cells. Among these, the IC50 of flubendazole on EC9706 was about $1.8 \mu \mathrm{M}$, and the IC50 of flubendazole on TE1 was about 2.2 $\mu \mathrm{M}$ (Figure 1B). In the following experiments, EC9706 and TE1 cell lines were prepared for further studies (Figure 1C).

Apoptosis in cells was further analyzed by flow cytometry. As shown in Figure 2A, exposing EC9706 and TE1 cells to flubendazole for 24 hours led to a significant increase of Annexin $\mathrm{V}^{+}$population. We then evaluated the status of the caspase substrate, PARP, in these cells by immunoblotting. As shown in Figure 2B, flubendazole induced the cleavages of
PARP in a dose-dependent manner. Further, immunoblotting assay showed that the anti-apoptotic protein Bcl-2 was downregulated by flubendazole treatment, and the pro-apoptotic protein Bim was upregulated in flubendazole-treated cells (Figure 2C). These results demonstrated that flubendazole inhibited ESCC cell survival by inducing cell apoptosis.

\section{Flubendazole inhibits NF-kB signaling in ESCC cells}

$\mathrm{NF}-\kappa \mathrm{B}$ signaling is hyperactivated in ESCC cells and critical for ESCC cell survival. ${ }^{11,17,18}$ But the expression levels of $\mathrm{NF}-\kappa \mathrm{B}$ components have hardly been visualized in different ESCC cell lines. Hence, seven ESCC cell lines were collected for immunoblotting against NF- $\mathrm{BB}$ p 65. As shown in Figure $3 \mathrm{~A}, \mathrm{NF}-\kappa \mathrm{B}$ p 65 was universally elevated in all seven ESCC cell lines, and phosphorylated p65 was also highly expressed in six of the seven cell lines examined, which suggested that NF- $\kappa \mathrm{B}$ signaling was important for ESCC cells.

To evaluate whether flubendazole inhibited NF- $\kappa B$ signaling in ESCC cells, EC9706 and TE1 cells were treated
A<smiles>COC(=O)Nc1nc2ccc(C(=O)c3ccc(F)cc3)cc2[nH]1</smiles>

FBD

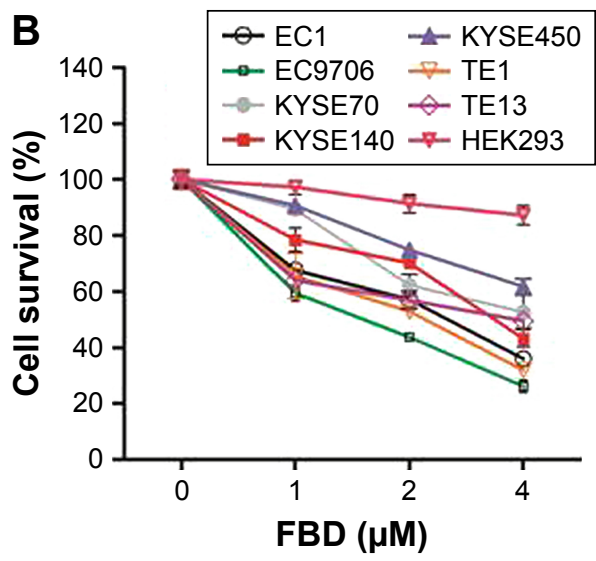

C

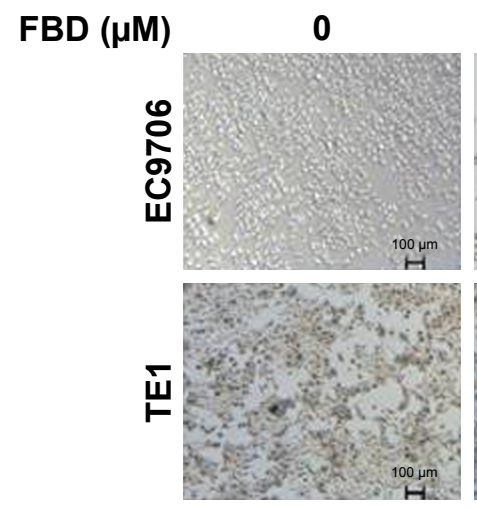

1

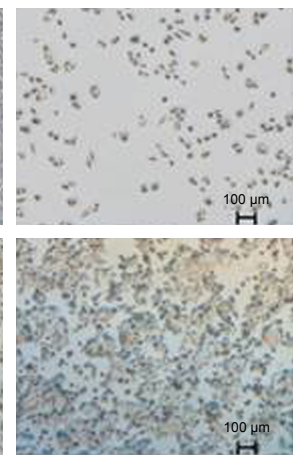

2

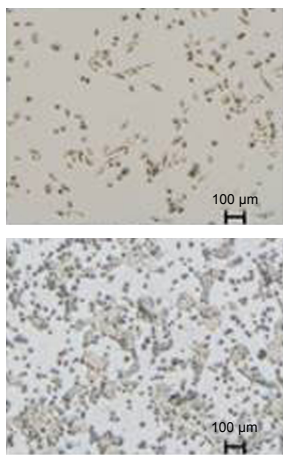

4

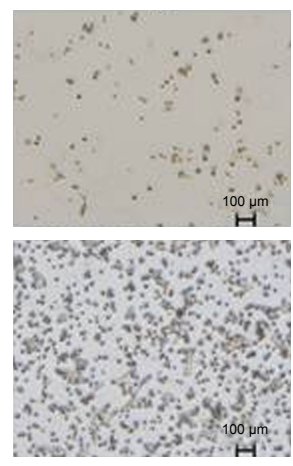

Figure I FBD inhibits cell survival in ESCC cells.

Notes: (A) Chemical structure of FBD. (B) ESCC cell lines ECI, EC9706, KYSE70, KYSEI40, KYSE450, TEI and TEI3, and a human renal epithelial cell line HEK293 were treated with indicated concentrations of FBD for 24 hours, followed by Cell Counting Kit-8 assay. (C) EC 9706 and TEI cells were treated with FBD for 24 hours, and then photos were taken by microscopy.

Abbreviations: ESCC, esophageal squamous cell carcinoma; FBD, flubendazole. 

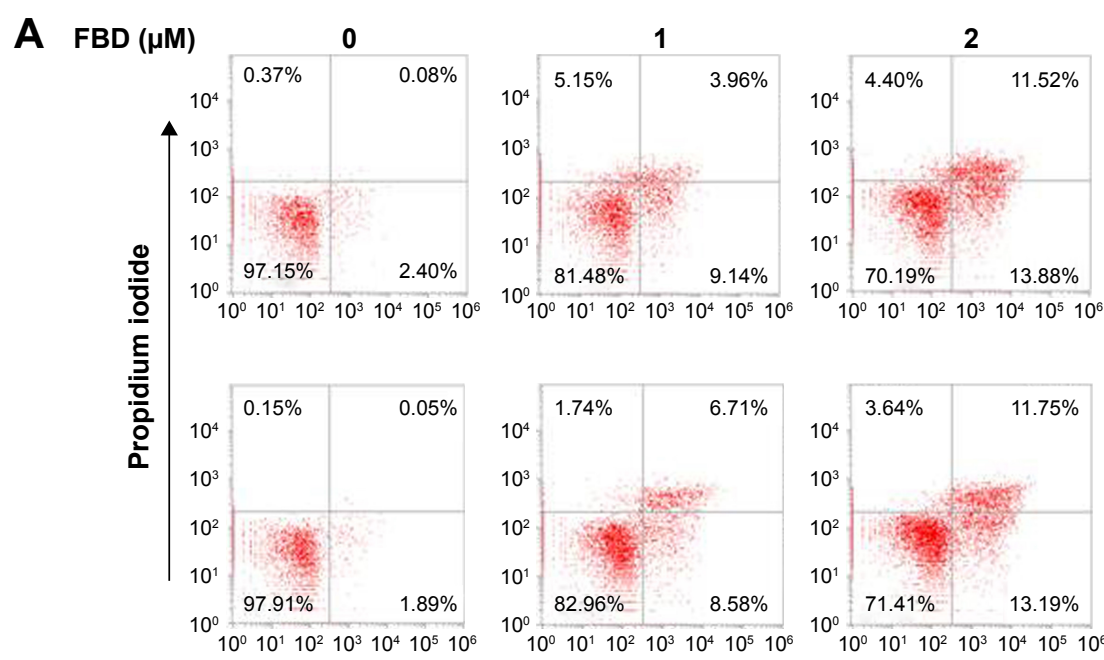

EC9706

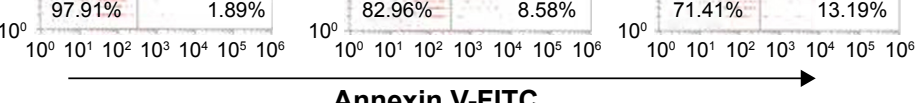

Annexin V-FITC

B

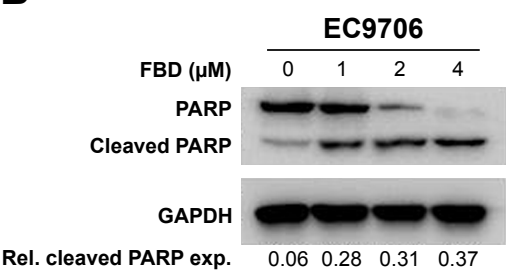

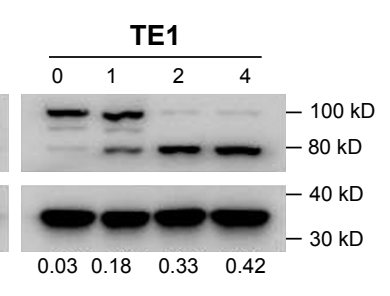

C

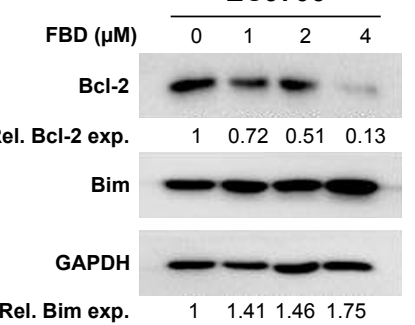

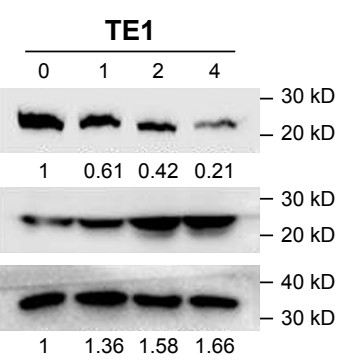

Figure 2 FBD induces cell apoptosis in ESCC cells.

Notes: (A) EC9706 and TEI cells were treated with different concentrations of FBD for 24 hours, and then cells were stained with Annexin V-FITC and PI for cell apoptosis analysis on a flow cytometer. (B) EC9706 and TEI cells were treated with increasing concentrations of FBD for 24 hours, and then the cells were prepared for immunoblotting against PARP. GAPDH was used as a loading control. (C) EC9706 and TEI cells were treated with FBD for 24 hours, and then the cells were prepared for immunoblotting against $\mathrm{Bcl}-2$, Bim, and GAPDH.

Abbreviations: ESCC, esophageal squamous cell carcinoma; FBD, flubendazole; NF- $\kappa B$, nuclear factor kappa B; TNF $\alpha$, tumor necrosis factor $\alpha$; Rel, relative; exp, expression.

with increasing concentrations of flubendazole for 24 hours. As shown in Figure 3B, the phosphorylated levels of p65 were downregulated by flubendazole in a concentrationdependent manner, but the total p65 level was not affected.

It is known that NF- $\mathrm{kB}$ p65 is also phosphorylated by stimulants such as TNF $\alpha$, followed by the activation of NF- $\kappa \mathrm{B}$ signaling pathway. ${ }^{10}$ Then, to assess whether flubendazole specifically inhibited NF- $\kappa B$ signaling, ESCC cells were starved overnight to decrease constitutive signaling.
Noteworthy, TNF $\alpha$ increased the phosphorylated NF- $\mathrm{KB}$ p65 in EC9706 and TE1 cells, which was also abolished by the pretreatment with flubendazole (Figure 3C). Next, a NF- $\kappa \mathrm{B}$ responsive element-driven luciferase reporter was constructed to evaluate flubendazole activity. As shown in Figure 3D, flubendazole suppressed baseline activity of NF-KB-driven luciferase. More impressively, it suppressed TNF $\alpha$-induced NF- $\kappa B$ activity by $\sim 50 \%$ compared with the control (Figure 3D).
A

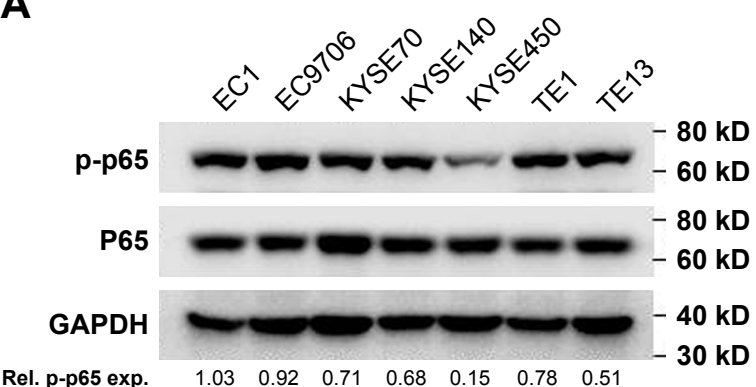

B

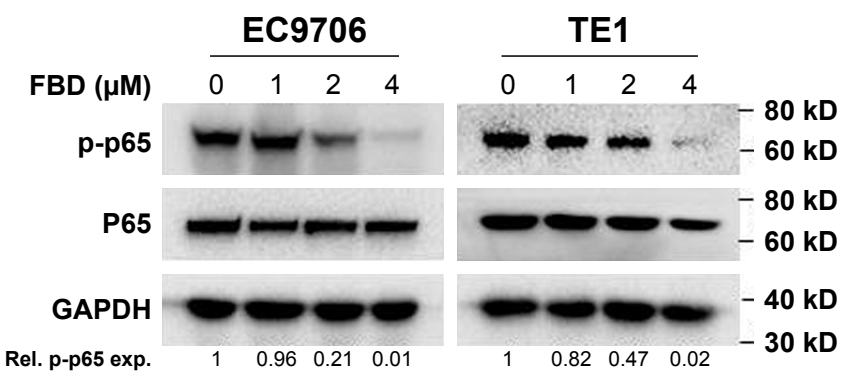

Figure 3 (Continued) 
C

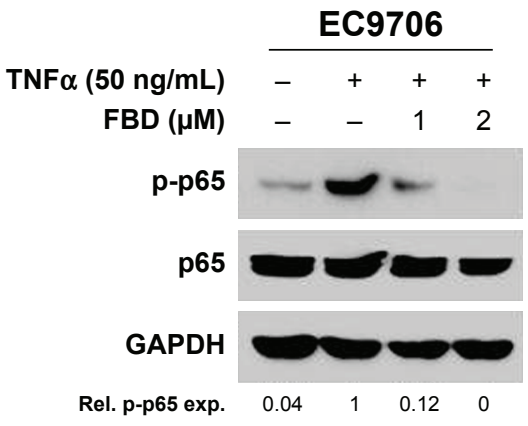

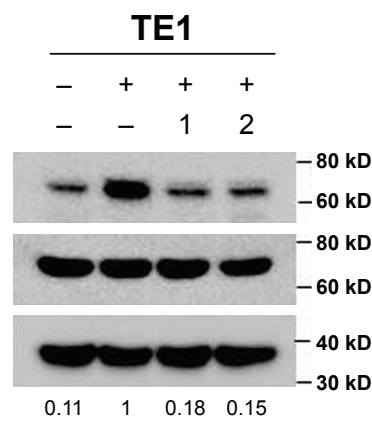

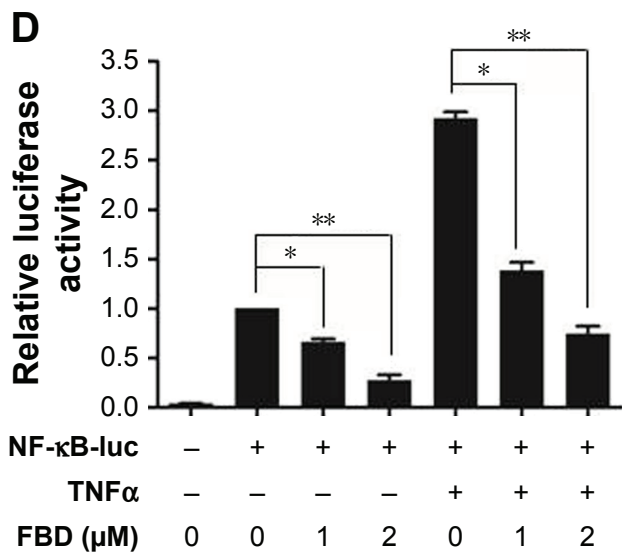

Figure $3 \mathrm{FBD}$ inhibits NF- $\mathrm{KB}$ signaling in ESCC cells.

Notes: (A) Seven ESCC cell lines were prepared for immunoblotting against p-p65, p65, and GAPDH. (B) EC9706 and TEI cells were treated with increasing concentrations of FBD for 24 hours, and then the cells were prepared for immunoblotting against p-p65 and p65. GAPDH was used as an internal control. (C) Following starvation overnight in serum-free medium, EC9706 and TEI cells were treated with increasing concentrations of FBD for 6 hours, and then stimulated with TNF $\alpha$ ( 50 ng/mL) for 20 minutes, followed by immunoblotting against p-p65, p65, and GAPDH. (D) EC9706 cells were transfected with vector or NF-kB-luc along with the internal control Renilla using Lipofectamine ${ }^{\circledR} 2000$ for 24 hours, and then the cells were treated with indicated concentrations of FBD for 12 hours. Luciferase activity was then measured followed by stimulation with TNF $\alpha$ or vehicle for 20 minutes. $* P<0.05$, $* * P<0.0$ I.

Abbreviations: ESCC, esophageal squamous cell carcinoma; FBD, flubendazole; NF-кB, nuclear factor kappa B; TNF $\alpha$, tumor necrosis factor $\alpha$; Rel, relative; exp, expression.

\section{Flubendazole inhibits IKK activation in ESCC cells}

To understand the mechanisms of inhibiting NF- $\mathrm{KB}$ p65 phosphorylation by flubendazole, the expression levels of upstream regulatory molecules, including $\mathrm{I} \kappa \mathrm{B} \alpha$, IKK $\alpha$, and IKK $\beta$, were evaluated in EC9706 and TE1 cells. ${ }^{19}$ As shown in Figure 4A, flubendazole inhibited the phosphorylation of I $\kappa \mathrm{B} \alpha$ dose-dependently, accompanied by an increase of
A

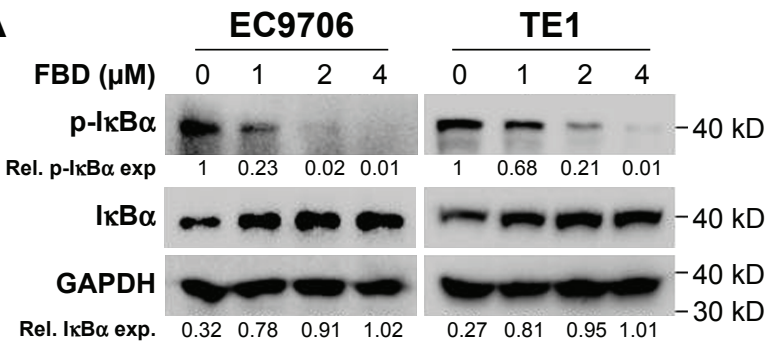

C

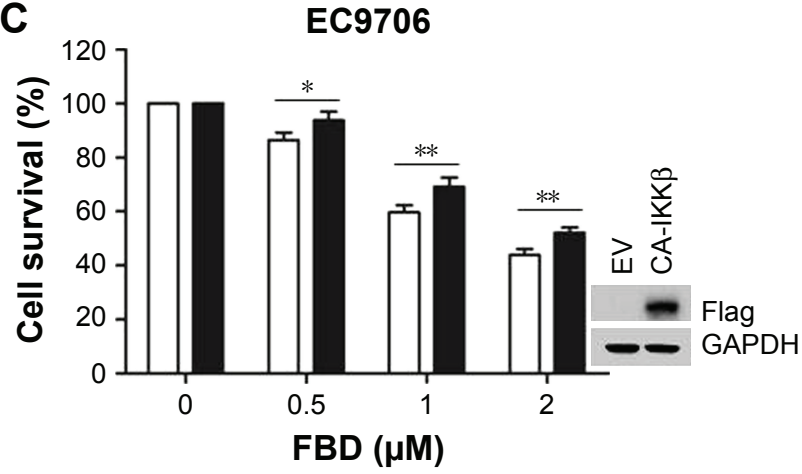

B

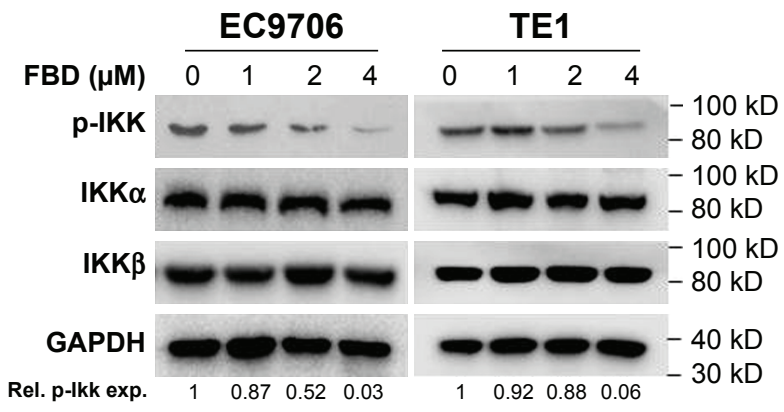

D

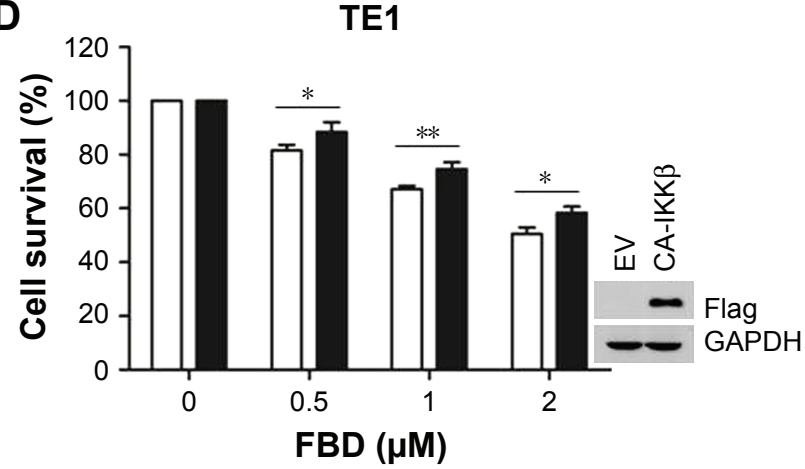

Figure 4 FBD inhibits IKK activation in ESCC cells.

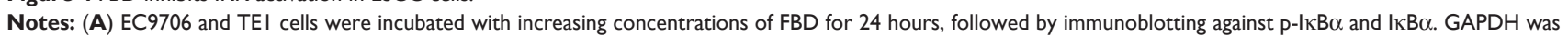
used as an internal control. (B) EC9706 and TEI cells were treated with FBD for 24 hours, and then cells were prepared for immunoblotting against P-IKK, IKK $\alpha$, IKK $\beta$, and GAPDH. (C) EC9706 cells were transfected with CA-IKK $\beta$ or empty vector for 24 hours, and then cells were treated with increasing concentrations of FBD for 24 hours, followed by CCK-8 assay. (D) TEI cells were transfected with CA-IKK $\beta$ or empty vector for 24 hours, and then the cells were treated with increasing concentrations of FBD for 24 hours, followed by CCK-8 assay. $* P<0.05$, $* * P<0.01$.

Abbreviations: ESCC, esophageal squamous cell carcinoma; FBD, flubendazole; IKK, IKB $\alpha$ kinase; EV, Empty vector; Rel, relative; exp, expression. 


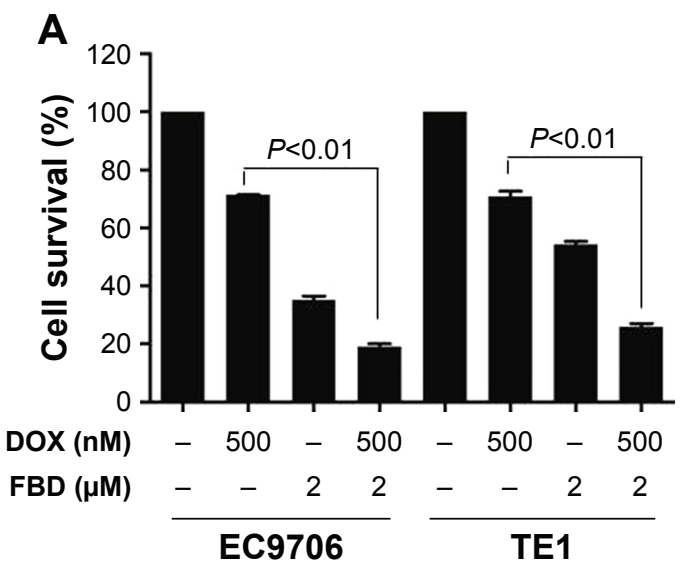

B

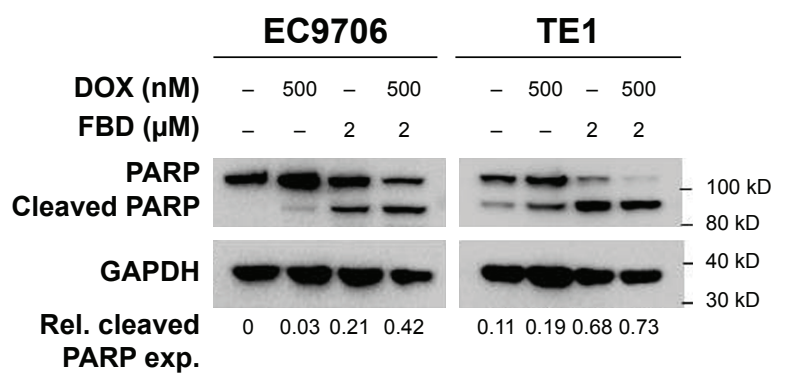

Figure 5 FBD enhances the cytotoxicity of DOX in ESCC cells.

Notes: (A) EC9706 and TEI cells were treated with 500 nM DOX for 24 hours in the presence or absence of $2 \mu$ M FBD, followed by CCK-8 assay. (B) EC9706 and TEI cells were treated with $500 \mathrm{nM}$ DOX for 24 hours in the presence or absence of $2 \mu \mathrm{M}$ FBD, and then the cells were lysed for immunoblotting against PARP and GAPDH. Abbreviations: CCK-8, Cell Counting Kit-8; DOX, doxorubicin; ESCC, esophageal squamous cell carcinoma; FBD, flubendazole; Rel, relative; exp, expression.

total I $\mathrm{IB} \alpha$ in both of EC9706 and TE1 cells. Moreover, the phosphorylation levels of IKKs were mostly diminished upon flubendazole treatment, but total IKK $\alpha$ and IKK $\beta$ were not affected in EC9706 and TE1 cells (Figure 4B).

To further evaluate the role of IKK inhibition, a constitutively activated IKK $\beta$ (CA-IKK $\beta$ ) with a Flag tag was constructed. ${ }^{16}$ As shown in Figure 4C and D, when EC9706 and TE1 cells were transfected with CA-IKK $\beta$, flubendazoleinduced cell survival inhibition was significantly attenuated, which suggested that IKK was involved in the process. These results demonstrated that blocking IKK activation was important for the inhibitory action of flubendazole on $\mathrm{NF}-\kappa \mathrm{B}$ signaling in ESCC cells.

\section{Flubendazole enhances the cytotoxicity of doxorubicin in ESCC cells}

Doxorubicin is one of the chemotherapeutic agents used for treating ESCC in clinic, ${ }^{20,21}$ but resistance to this drug has been frequently found in ESCC. ${ }^{22,23}$ A recent study showed that suppressing NF- $\mathrm{KB}$ signaling sensitized tumor cells to doxorubicin, ${ }^{5}$ which led us to examine whether flubendazole affected the effect of doxorubicin on ESCC cells. As shown in Figure 5A, doxorubicin or flubendazole alone led to $\sim 30 \%$ and $\sim 60 \%$ reduction of viability, respectively, in both EC9706 and TE1 cells. When the cells were treated with both drugs simultaneously, the viability reduction increased to $\sim 80 \%$ (Figure $5 \mathrm{~A}$ ). Flubendazole and doxorubicin also acted synergistically to induce PARP cleavages (Figure 5B), which indicated that flubendazole significantly enhanced the cytotoxic action of doxorubicin on ESCC cells.

\section{Discussion}

In this study, the anthelmintic drug flubendazole was found to be a novel NF- $\kappa \mathrm{B}$ inhibitor and showed significant antitumor activity by suppressing NF- $\mathrm{\kappa B}$ signaling in ESCC cells. Interestingly, flubendazole has been reported to exert obvious anti-tumor activity in several tumors. It has been reported that flubendazole showed preclinical activities in leukemia and myeloma by inhibiting microtubule function. ${ }^{24}$ In neuroblastoma, flubendazole induced neuroblastoma cell death by triggering cell apoptosis. ${ }^{25}$ And in breast cancer, flubendazole overcame trastuzumab resistance by targeting cancer stem-like properties and HER2 signaling in HER2positive breast cancer. ${ }^{26}$ Flubendazole could also inhibit glioma proliferation by $\mathrm{G} 2 / \mathrm{M}$ cell cycle arrest and being pro-apoptotic. ${ }^{27}$ Also, it has been reported that flubendazole elicited anti-metastatic effects in triple-negative breast cancer via STAT3 inhibition. ${ }^{28}$ Thus, flubendazole may be an effective drug for several types of tumors, although the common mechanism responsible for its action in different tumors is not confirmed.

The canonical NF- $\kappa B$ signaling pathway comprises extracellular stimuli, IKK activation, I $\kappa \mathrm{B} \alpha$ phosphorylation and degradation, p65/p50 nuclear translocation, NF- $\mathrm{kB}-\mathrm{DNA}$ binding, and NF- $\mathrm{KB}$ transactivation, all of which have been implicated as the targets for NF- $\kappa \mathrm{B}$ inhibitors' discovery. ${ }^{29}$ In this study, NF- $\kappa B$ was found to be activated in different ESCC cell lines (Figure 3A), and flubendazole significantly suppressed both the constitutive and TNF $\alpha$-induced NF- $\kappa \mathrm{B}$ p65 activation (Figure 3B-D). The IKKs are key kinases

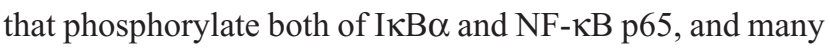


NF- $\kappa B$ inhibitors, which induce tumor cell apoptosis by suppressing IKK activation, have been identified..$^{30}$ Our study showed that, similar to IKK inhibitors, flubendazole also suppressed NF- $\mathrm{KB}$ p 65 phosphorylation by inhibiting IKK activation (Figure 4). Although several different mechanisms, such as specifically binding to tubulin, ${ }^{31}$ dysregulating cuticle-associated genes' expression, ${ }^{32}$ and oxidative damage,$^{33}$ have been reported for the anthelmintic action of flubendazole, it is still not clear how flubendazole affects IKK activation.

Moreover, flubendazole-induced ESCC cell survival inhibition was dependent on IKK activation level. As shown in Figure 4C and D, EC9706 and TE1 cells with CA-IKK $\beta$ are resistant to flubendazole compared with cells harboring empty vector. In addition, NF- $\mathrm{KB}$ signaling was activated in ESCC cell lines, and flubendazole could significantly suppress NF- $\mathrm{KB}$ activation (Figure 3). These results indicated that NF- $\kappa B$ signaling was required for ESCC cell survival, and some chemicals such as flubendazole could target NF- $\kappa \mathrm{B}$ signaling, which could be used for ESCC treatment.

\section{Conclusion}

In conclusion, the present study demonstrated that the anthelmintic drug flubendazole exerted its anti-tumor activity by suppressing NF-אB signaling in ESCC cells. This study suggests that flubendazole could be re-purposed for ESCC treatment in the clinic in the future.

\section{Acknowledgments}

This study was supported by the General Project of Science and Technology Development Fund of Nanjing Medical University (Grant No. 2013NJMU225). The authors thank Dr Jerry $\mathrm{Xu}$ for his discussion on this project.

\section{Disclosure}

The authors report no conflicts of interest in this work.

\section{References}

1. Zou J, Li S, Chen Z, et al. A novel oral camptothecin analog, gimatecan, exhibits superior antitumor efficacy than irinotecan toward esophageal squamous cell carcinoma in vitro and in vivo. Cell Death Dis. 2018;9(6):661.

2. Zeng H, Zheng R, Guo Y, et al. Cancer survival in China, 2003-2005: a population-based study. Int J Cancer. 2015;136(8):1921-1930.

3. Zhang J, Jiang D, Li X, et al. Establishment and characterization of esophageal squamous cell carcinoma patient-derived xenograft mouse models for preclinical drug discovery. Lab Invest. 2014;94(8):917-926.

4. Kano Y, Konno M, Kawamoto K, et al. Novel drug discovery system for cancer stem cells in human squamous cell carcinoma of the esophagus. Oncol Rep. 2014;31(3):1133-1138.
5. Xu X, Wang J, Han K, et al. Antimalarial drug mefloquine inhibits nuclear factor kappa B signaling and induces apoptosis in colorectal cancer cells. Cancer Sci. 2018;109(4):1220-1229.

6. Coussens NP, Braisted JC, Peryea T, Sittampalam GS, Simeonov A, Hall MD. Small-molecule screens: a gateway to cancer therapeutic agents with case studies of food and drug administration-approved drugs. Pharmacol Rev. 2017;69(4):479-496.

7. Roy P, Sarkar U, Basak S. The NF- $\kappa$ B activating pathways in multiple myeloma. Biomedicines. 2018;6(2):59.

8. Chen G, Han K, Xu X, et al. An anti-leishmanial thiadiazine agent induces multiple myeloma cell apoptosis by suppressing the nuclear factor kappaB signalling pathway. Br J Cancer. 2014;110(1):63-70.

9. Sacht G, Märten A, Deiters U, et al. Activation of nuclear factorkappaB in macrophages by mycoplasmal lipopeptides. Eur J Immunol. 1998;28(12):4207-4212.

10. Rayet B, Gélinas C. Aberrant rel/nfkb genes and activity in human cancer. Oncogene. 1999;18(49):6938-6947.

11. Lehman HL, Kidacki M, Warrick JI, Stairs DB. NFkB hyperactivation causes invasion of esophageal squamous cell carcinoma with EGFR overexpression and p120-catenin down-regulation. Oncotarget. 2018;9(13):11180-11196.

12. Tian F, Yang X, Liu Y, et al. Constitutive activated STAT3 is an essential regulator and therapeutic target in esophageal squamous cell carcinoma. Oncotarget. 2017;8(51):88719-88729.

13. Han K, Xu X, Chen G, et al. Identification of a promising PI3K inhibitor for the treatment of multiple myeloma through the structural optimization. J Hematol Oncol. 2014;7(1):9.

14. Chen G, Xu X, Tong J, et al. Ubiquitination of the transcription factor c-MAF is mediated by multiple lysine residues. Int J Biochem Cell Biol. 2014;57:157-166.

15. Xu X, Han K, Tang X, et al. The ring finger Protein RNF6 induces leukemia cell proliferation as a direct target of Pre-B-cell leukemia homeobox 1. J Biol Chem. 2016;291(18):9617-9628.

16. Delhase M, Hayakawa M, Chen Y, Karin M. Positive and negative regulation of IkappaB kinase activity through IKKbeta subunit phosphorylation. Science. 1999;284(5412):309-313.

17. Tian F, Zhang C, Tian W, et al. Comparison of the effect of p65 siRNA and curcumin in promoting apoptosis in esophageal squamous cell carcinoma cells and in nude mice. Oncol Rep. 2012;28(1):232-240.

18. Tian F, Fan T, Zhang Y, Jiang Y, Zhang X. Curcumin potentiates the antitumor effects of 5-FU in treatment of esophageal squamous carcinoma cells through downregulating the activation of NF- $\kappa \mathrm{B}$ signaling pathway in vitro and in vivo. Acta Biochim Biophys Sin. 2012;44(10): 847-855.

19. Zhong H, May MJ, Jimi E, Ghosh S. The phosphorylation status of nuclear NF-KB determines its association with CBP/p300 or HDAC-1. Molecular Cell. 2002;9(3):625-636.

20. Honda M, Miura A, Izumi Y, et al. Doxorubicin, cisplatin, and fluorouracil combination therapy for metastatic esophageal squamous cell carcinoma. Dis Esophagus. 2010;23(8):641-645.

21. Lee HH, Ye S, Li XJ, Lee KB, Park MH, Kim SM. Combination treatment with paclitaxel and doxorubicin inhibits growth of human esophageal squamous cancer cells by inactivation of Akt. Oncol Rep. 2014;31(1):183-188.

22. Yu L, Wu WK, Li ZJ, et al. Enhancement of doxorubicin cytotoxicity on human esophageal squamous cell carcinoma cells by indomethacin and 4-[5-(4-chlorophenyl)-3-(trifluoromethyl)-1H-pyrazol-1-yl] benzenesulfonamide (SC236) via inhibiting P-glycoprotein activity. Mol Pharmacol. 2009;75(6):1364-1373.

23. Zhou Y, Hong L. Prediction value of miR-483 and miR-214 in prognosis and multidrug resistance of esophageal squamous cell carcinoma. Genet Test Mol Biomarkers. 2013;17(6):470-474.

24. Spagnuolo PA, Hu J, Hurren R, et al. The antihelmintic flubendazole inhibits microtubule function through a mechanism distinct from Vinca alkaloids and displays preclinical activity in leukemia and myeloma. Blood. 2010;115(23):4824-4833. 
25. Michaelis M, Agha B, Rothweiler F, et al. Identification of flubendazole as potential anti-neuroblastoma compound in a large cell line screen. Sci Rep. 2015;5(1):8202.

26. Kim YJ, Sung D, Oh E, et al. Flubendazole overcomes trastuzumab resistance by targeting cancer stem-like properties and HER2 signaling in HER2-positive breast cancer. Cancer Lett. 2018;412:118-130.

27. Zhou X, Liu J, Zhang J, Wei Y, Li H. Flubendazole inhibits glioma proliferation by G2/M cell cycle arrest and pro-apoptosis. Cell Death Discovery. 2018;4(1):18.

28. Oh E, Kim YJ, An H, et al. Flubendazole elicits anti-metastatic effects in triple-negative breast cancer via STAT3 inhibition. Int J Cancer. 2018;143(8):1978-1993.

29. Gilmore TD, Herscovitch M. Inhibitors of NF-kappaB signaling: 785 and counting. Oncogene. 2006;25(51):6887-6899.
30. Viatour P, Merville MP, Bours V, Chariot A. Phosphorylation of NFkappaB and IkappaB proteins: implications in cancer and inflammation. Trends Biochem Sci. 2005;30(1):43-52.

31. Čáňová K, Rozkydalová L, Rudolf E. Anthelmintic flubendazole and its potential use in anticancer therapy. Acta Medica. 2017;60(1):5-11.

32. O’Neill M, Ballesteros C, Tritten L, et al. Profiling the macrofilaricidal effects of flubendazole on adult female Brugia malayi using RNAseq. Int J Parasitol Drugs Drug Resist. 2016;6(3):288-296.

33. Maté ML, Geary T, Mackenzie C, Lanusse C, Virkel G. Species differences in hepatic biotransformation of the anthelmintic drug flubendazole. J Vet Pharmacol Ther. 2017;40(5):493-499.

\section{Publish your work in this journal}

OncoTargets and Therapy is an international, peer-reviewed, open access journal focusing on the pathological basis of all cancers, potential targets for therapy and treatment protocols employed to improve the management of cancer patients. The journal also focuses on the impact of management programs and new therapeutic agents and protocols on

\section{Dovepress}

patient perspectives such as quality of life, adherence and satisfaction. The manuscript management system is completely online and includes a very quick and fair peer-review system, which is all easy to use. Visit http://www.dovepress.com/testimonials.php to read real quotes from published authors. 